\title{
Concurso de Anteproyecto de Intervención y Puesta en Valor del Monumento Histórico Patio 29, Cementerio General
}

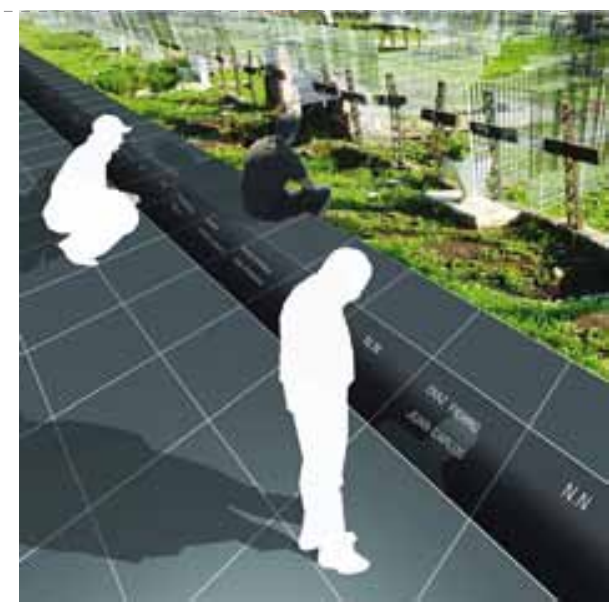

Primer premio.

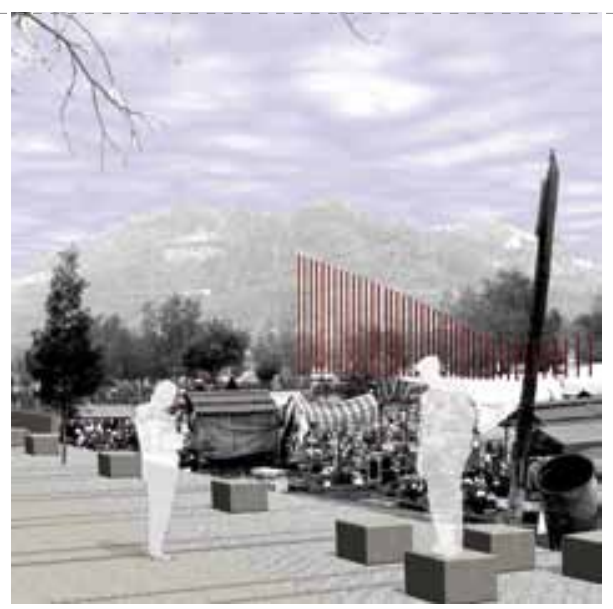

Segundo premio.

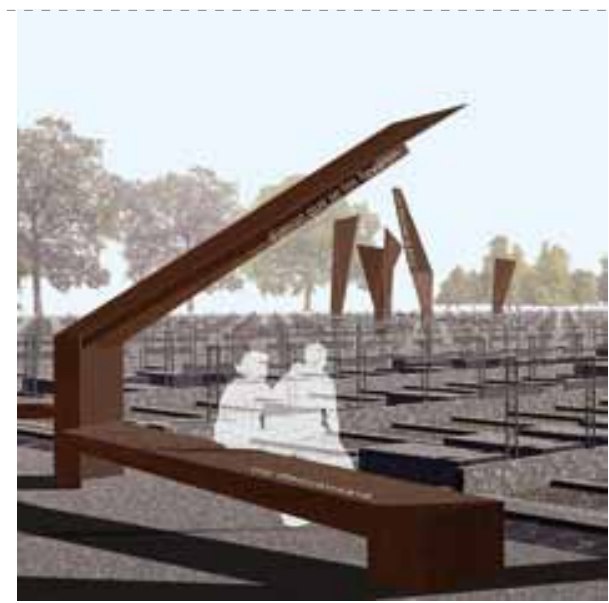

Teгcer premio.
En el marco de una política de reconocimiento y puesta en valor de aquellos sitios vinculados a la violación de derechos humanos entre los años 1973 y 1990, el Estado de Chile, a través del Consejo de Monumentos Nacionales, declaró Monumento Histórico a un conjunto de lugares utilizados como recintos de detención o zonas donde se sepultaron a las víctimas de tales agresiones. Dentro de esta declaración está incorporado el Patio 29 del Cementerio General, espacio paradigmático de la persecución política en dictadura y de la historia reciente de nuestro país. A partir de este nombramiento, el Consejo de Monumentos Nacionales Ilamó a concurso para la ejecución de un anteproyecto de intervención y puesta en valor del Patio 29, con el afán de mantener y preservar el lugar como antecedente de la memoria histórica de Chile.

\section{El Patio 29 del Cementerio General, fue} utilizado como lugar de ocultamiento de las víctimas de la dictadura militar, representación de una política de engaño y agresión, pero también, es un símbolo de la lucha por la recuperación de la democracia, el acceso a la verdad y a la justicia. En tal dirección, el llamado efectuado en abril del año 2008, estableció la presentación de un anteproyecto y de un manual de conservación, que permitiera la mantención en el tiempo de la intervención ganadora. Junto con la propuesta propiamente tal, el proyecto debía incluir la presencia de un elemento conmemorativo que diera cuenta de los hechos ocurridos en el lugar y del nombramiento del mismo como Monumento Histórico por parte del Estado de Chile. Además, la cercanía del lugar con la tumba de Víctor Jara, permitió que los organizadores incorporaran en la propuesta, la puesta en valor del lugar donde se encuentra los restos del destacado artista popular chileno.

Finalmente, el concurso efectuó la premiación de los tres primeros lugares, siendo el primer lugar el equipo encargado de la materialización y construcción del proyecto presentado, actualmente en fase de desarrollo. Presentaremos las imágenes y memorias explicativas de los tres primeros lugares. 
Primer Lugar.

Equipo: Daphne Agosin, Gonzalo Cáceres, Ignacio García, Liliana de Simone, Daniel Muñoz, Cristián Robertson, Valentina Rozas, Sebastián Silva y Arturo Torres.

\section{Memor i a}

\section{Diagnóstico}

Relegado a la condición de patio trasero, e Patio 29 se ubica distante de los accesos y vías principales al Cementerio General. Confundido con el resto de los Patios de Tierra, su fisonomía deteriorada contrasta con su condición de único monumento histórico de Recoleta. La historia incierta que denuncia el Patio 29 invita a una intervención que evidencie su condición de caso abierto. Proyectar una intervención del patio y su entorno inmediato, exige el diseño de un equipamiento que acoja al visitante y lo invite a reunirse, contemplar y reflexionar individual o colectivamente. Mientras su materialidad corroída invita a un proyecto que encuadre su estado actual, la homogeneidad que el sitio exhibe, demanda una diferenciación que enfrente el anonimato.

\section{Propuesta}

La primera respuesta es enmarcar el Patio 29. A continuación el marco se convierte en mobiliario y soporte informativo. Para el visitante la circulación peatonal puede ser a través de la rampa que se extiende de norte a sur o desde las escaleras que se despliegan hacia el norte y el poniente. Sobre la

plataforma el visitante dispondrá de una nueva perspectiva sobre el patio.

Hacia el poniente y a nivel de suelo, el marco programático se prolonga hasta alcanzar el nicho donde yace Víctor Lidio Jara Martínez.
Frente a los restos del compositor se abre una plaza de la música que se articula con el Patio 29 a través de una secuencia de filamentos verticales. Dispuestos en progresión descendente hacia el oriente, las esculturas sonoras reproducen las notas musicales a través del movimiento. Mientras los sonidos graves se despliegan hacia el Patio, enmarcando las tumbas correspondientes a los detenidos desaparecidos, las notas más altas culminan frente al nicho de Jara.

Al modo de una progresión, los filamentos verticales enmarcan las tumbas, el marco programático encuadra el Patio y nuestra propuesta se extiende y dispersa por la totalidad del Cementerio, a través de baldosas orientadoras. Este soporte se emplaza en lugares de alta visibilidad apuntando siempre hacia el Patio 29

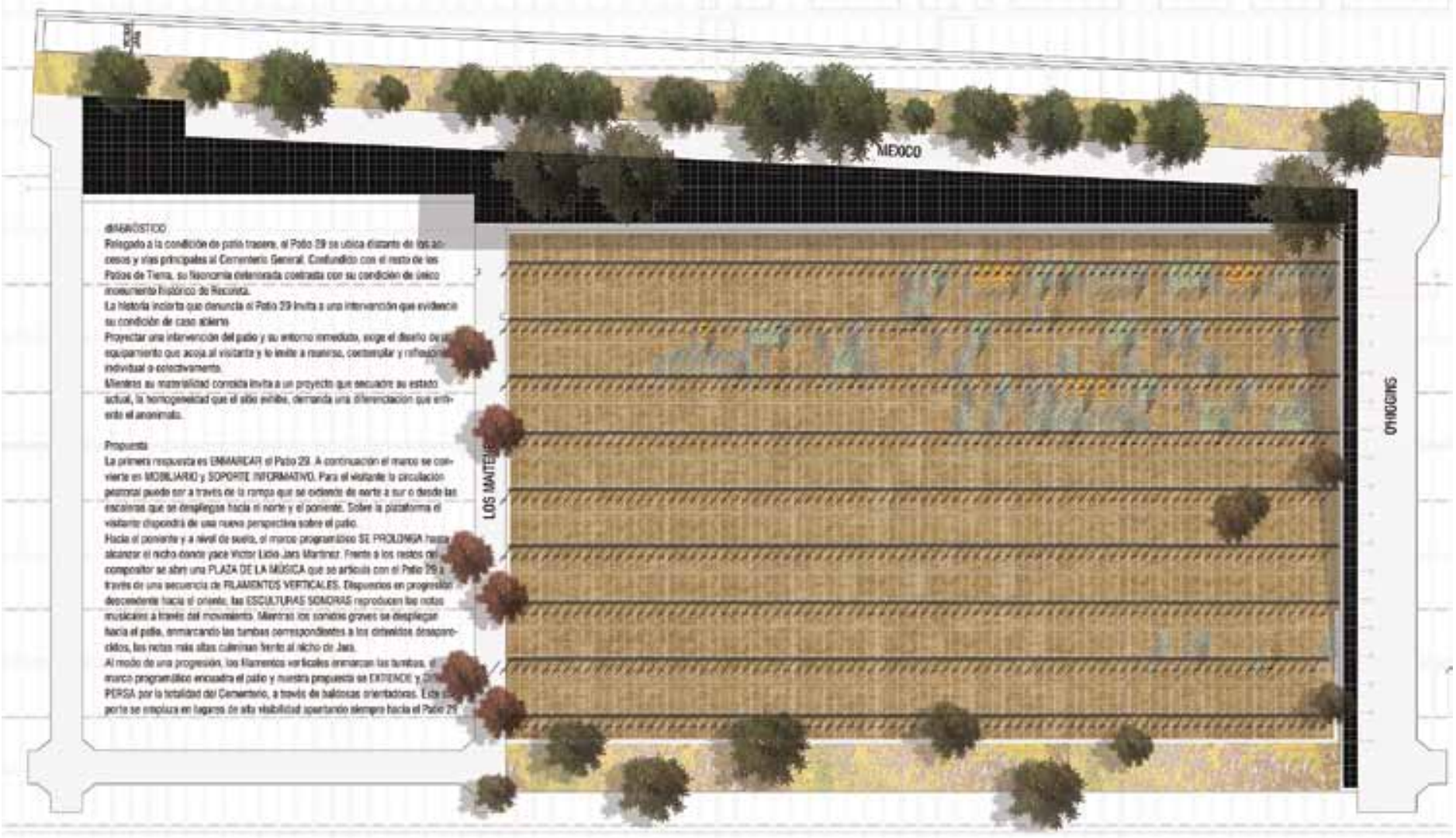



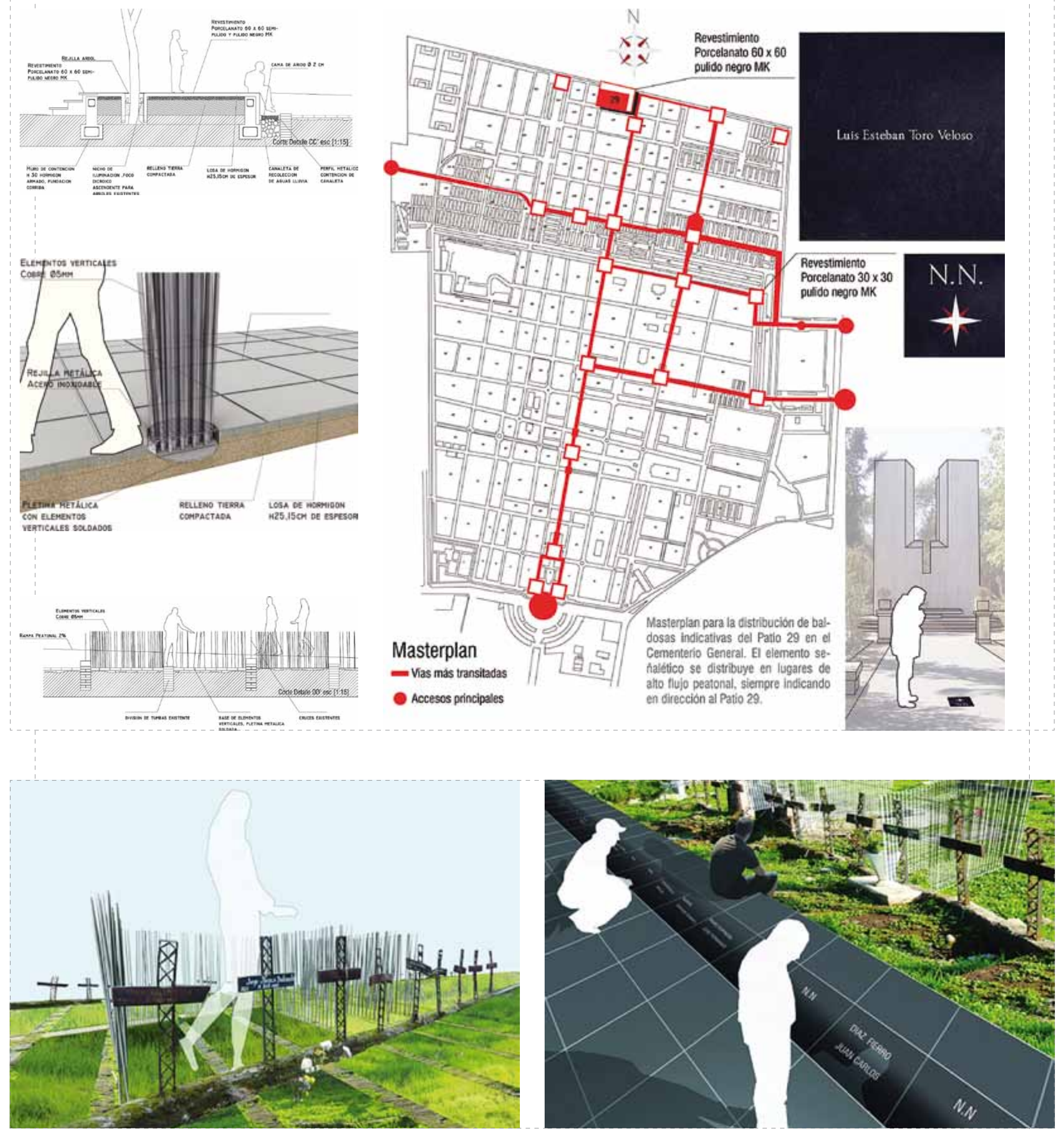

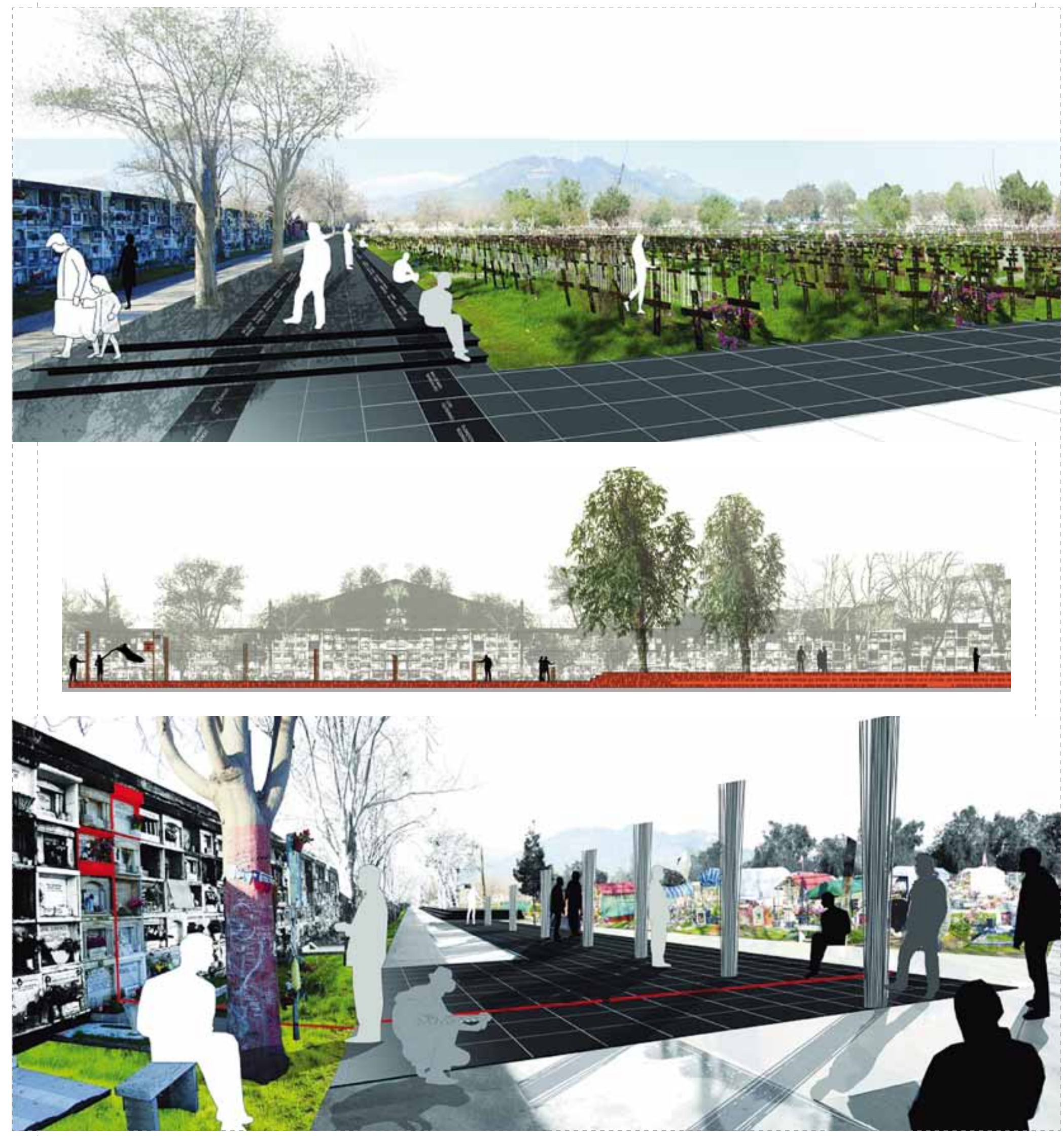


\section{Segundo Lugar.}

Equipo: Daniela Flisfisch, Diego Gómez, Claudia Jiménez, Ricardo Muñoz y Catalina Tuca.

\section{Memor i a}

\section{objetivos}

Recuperar un espacio ciudadano para la conmemoración y el recuerdo de las víctimas de la dictadura y de todas aquellas personas inhumadas en el Patio 29, de modo de apoyar las acciones conducentes a mantener viva la memoria colectiva de nuestro país.

Otorgarle al Patio 29 una connotación de espacio simbólico; de recuperación histórica para y por el respeto de los derechos humanos.

Destacar y valorizar el Patio 29 interviniendo en sus bordes, poniendo en valor los elementos existentes para develar su historia oculta e impregnarla de resignificación y sanación.

Comunicar y conectar el espacio del Patio 29 con su contexto social y geográfico, correspondiente, en distintos niveles, a cementerio, al barrio, a los cerros, a la cordillera y en última instancia a la ciudad.

Extrapolar los hechos ocurridos en el Patio 29, vinculando esta área con otros espacios de memoria y conmemoración a nivel nacional.

\section{Estrategia}

Acción de borde: Regenerar el borde del Patio 29 en busca de mejorar la zona que lo envuelve y limita.

La franja correspondiente a calle México se extiende hacia el poniente para conectar y establecer un tránsito hacia la tumba de Víctor
Jara. Este espacio se configura a partir de dos niveles de suelo que permiten visualizar el lugar desde diferentes puntos de vista y simbolizar así las capas de la memoria.

\section{Nivel terreno natural: (Cota 0$)$}

La intervención propone nuevos recorridos y conexiones visuales, generando una aproximación a este espacio simbólico desde otra perspectiva, de modo de volver a mirar los elementos preexistentes desde otros ángulos, otros ritmos y otros sonidos. Se conforman así zonas de permanencia y contemplación.

2. Fosa: (Cota -1.08)

Este espacio corresponde al centro o corazón del memorial, que en un nivel hundido se constituye en espacio de recogimiento e indagación de las capas profundas de la memoria histórica. Se recuerdan los hechos de manera poética a través de la sensación corporal y visual de cercanía con la tierra, la cuál, de forma simbólica, aparece a través de una placa de vidrio que devela en su superficie los acontecimientos acaecidos. Se propone la utilización de textos que representen a los familiares de las víctimas y a las agrupaciones de detenidos desaparecidos.

\section{Activación de la matriz}

Las sepulturas conforman una trama ortogonal, en base a la cual la estructura del proyecto se origina. Esta trama es la base tanto para la apertura y comunicación del espacio como para su contención.

Por un lado, la trama se expande fuera de sus límites en forma de texturas pétreas sobre las cuatro calles laterales del Patio, y por otro, las líneas en dirección norte-sur marcan los puntos desde donde surgen los paramentos verticales en el límite sur del Patio. Estos paramentos emergen desde el suelo como símbolo material de las personas ausentes, en un gesto de vínculo entre el pasado y el presente, la muerte y la vida, la historia y la justicia, el individuo y la sociedad.

De esta forma, la sucesión de paramentos constituye tanto el hito reconocible del lugar, como el elemento de cierre con el patio siguiente, haciéndose visible desde la distancia, pero permaneciendo austero y leve para no violentar el espacio a su alrededor y dialogar con la geografía circundante.

\section{Materiales}

La propuesta considera la utilización de materiales pétreos como ripio, adoquines, concreto y acero, ya que se trata de materiales austeros, duraderos y de mínima mantención. Además el paso del tiempo sobre ellos les otorgará una textura y un valor adicional, que guarda relación con la estética propia del cementerio. Estos materiales se trabajarán en las distintas escalas de aproximación al proyecto, de modo de generar una lectura unitaria.

\section{Vegetación}

Se incorporan especies arbóreas de floración llamativa y hojas caducas que tiñan el espacio con tonalidades marcando las diferentes estaciones. La arborización existente se mantiene, ya que se trata de árboles simbólicos para las familias que han estado involucradas con la historia del Patio. Árboles propuestos y árboles existentes se complementan generando líneas de visión y creando espacios de sombra para la contemplación y la reflexión. Se incorporarán especies gramíneas que requieren de poco riego y mantención.
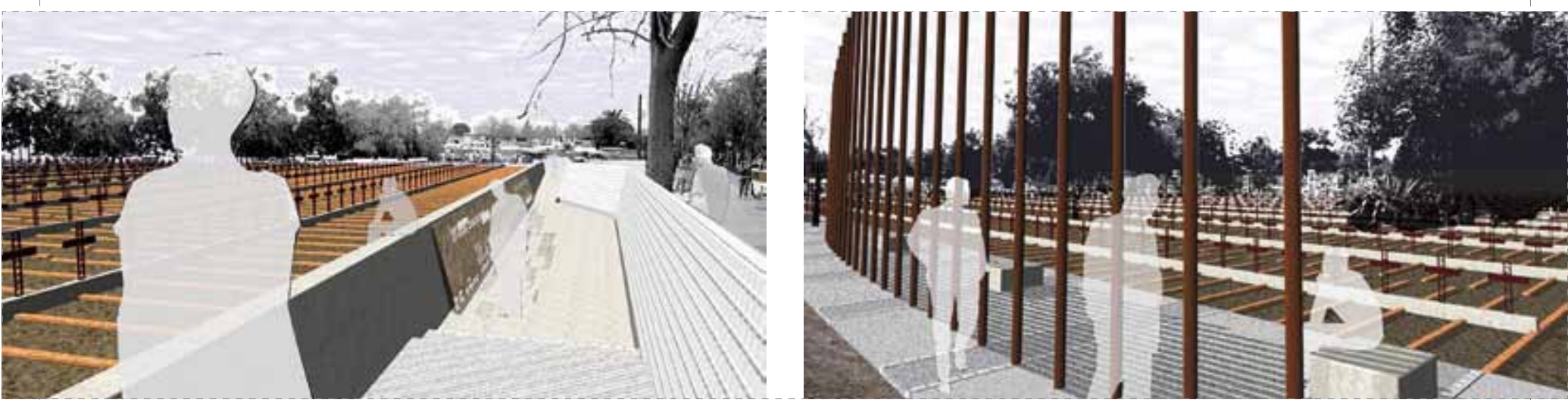


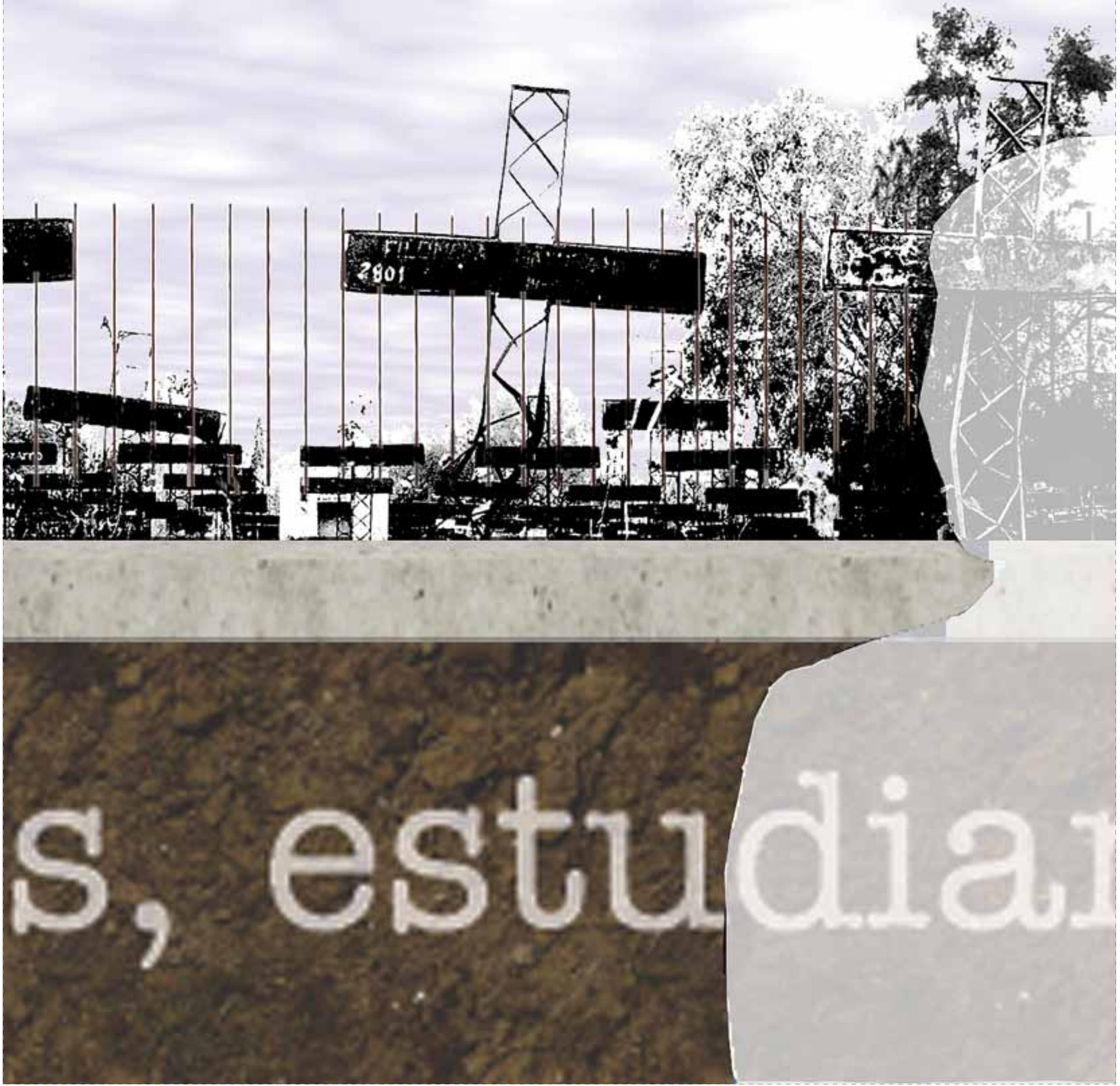



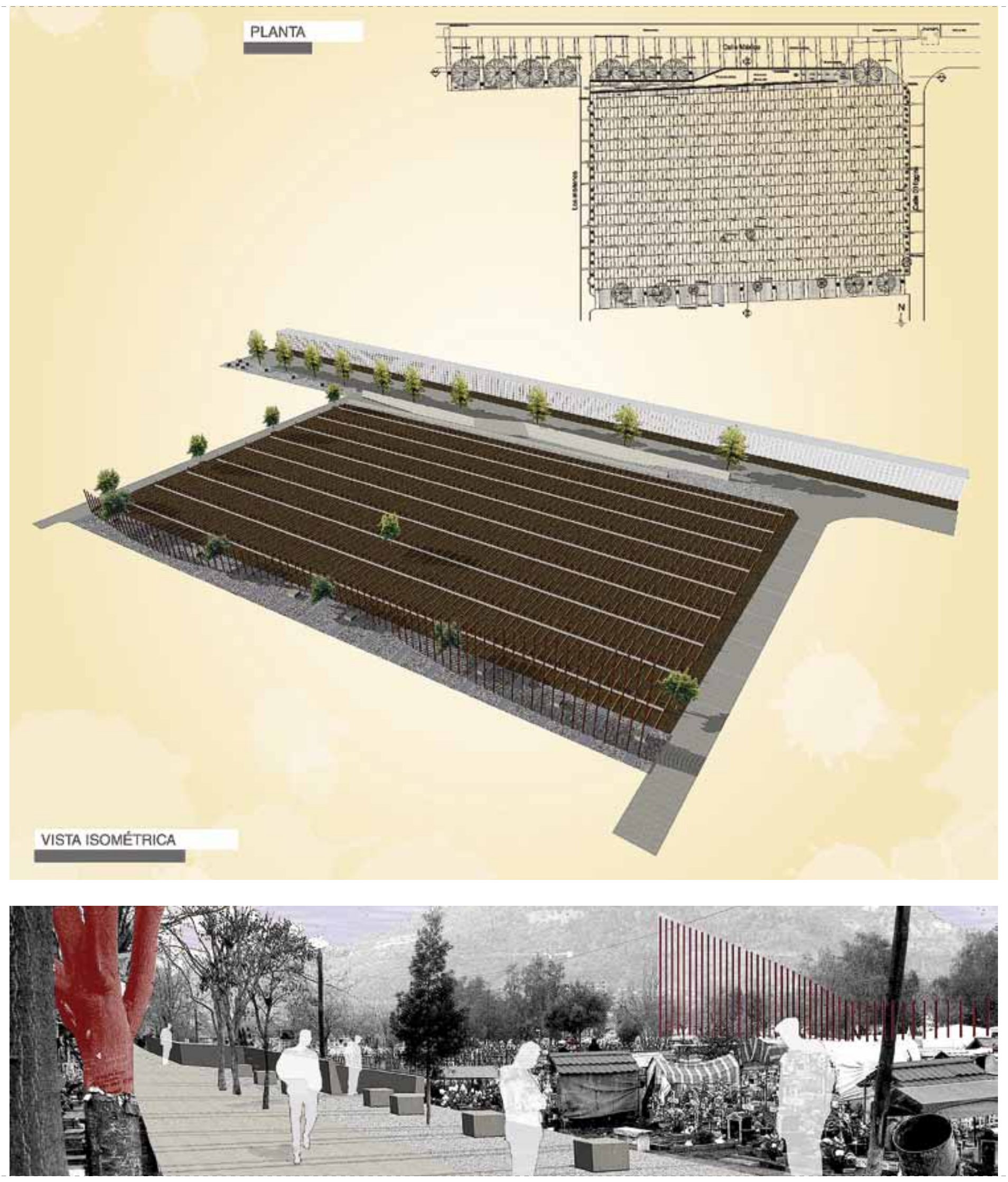


\section{Tercer Lugar.}

Equipo: m3 paisaje S.A. Andrew Harris, Claudia Illanes, Marcia Escobar, Rodrigo Mena, Pablo Cornejo y Carolina Becerra.

\section{Memoria}

\section{¿Qué memoria trae este memorial?}

La memoria de la historia, de las víctimas y de los familiares. La propuesta del memorial aquí presentado plantea tres decisiones centrales: poner en valor el lugar por su historia, poner en valor el lugar de las víctimas, poner en valor la perseverancia de los familiares.

\section{El valor del lugar por su historia}

El primer gesto de respeto hacia el Patio 29 es marcar el área de las sepulturas como un objeto singular, distinto y valioso, realzándolo de su entorno. Es poner una cinta en su perímetro que lo distinga y al mismo tiempo lo proteja.

Es por esto que el proyecto propone rodear el Patio con un borde construido, dado por una zanja de anchos variables, que contiene agua y que le da la distancia y respeto suficiente a los visitantes para entender estas sepulturas como un lugar especial. Esta zanja es la cinta que amarra el objeto histórico y a la vez que delimita una zona de ruinas, un sitio arqueológico. Las «ruinas» u objetos históricos son entonces limpiados y conservados en condiciones óptimas para su durabilidad.
En el interior, la idea es preservar las sepulturas con los elementos originales, sólo cubriendo con gravilla fina los espacios entre hileras de ladrillos, de manera de destacar la estructura de bordes, pasadizos y muretes que presenta este sistema de sepulturas. Todos los árboles, tanto en el interior como en el perímetro del Patio también se conservan.

En el ánimo de conservación y protección, el Patio 29 debe ser intervenido como trabajo de restauración constructiva, especialmente en aquellos aspectos que garanticen la durabilidad en el tiempo de la estructura de ladrillos y muretes (estabilidad del suelo, protección del agua, etc.), de manera de evitar su deterioro y a la larga, la pérdida de los elementos históricos.

La zanja entonces no es sólo un gesto simbólico, sino también una medida de orden constructivo, ya que actúa como el envoltorio de un recinto que debe ser protegido estructuralmente y del paso cotidiano de los visitantes.

\section{El valor de las victimas}

El segundo componente de la propuesta son los volúmenes que caracterizarían a las tumbas NN. Estas tumbas llevarían sobrepuestas, y como único objeto ajeno a las ruinas históricas, un volumen hecho de láminas de cristal que asemejan «lámparas» iluminadas desde su interior permanentemente, como una forma de expresar que estas tumbas son una memoria viva de las personas que aquí fueron enterradas. Estarían iluminadas las 24 horas del día, de manera que adquieren diferentes intensidades y tonalidades dependiendo de la hora del día, del tiempo, del momento. Es una luz eterna que nos lleva a reflexionar y a recordar la vida de los desaparecidos.

\section{El valor de los familiares}

El tercer paso de esta propuesta es el trabajo alrededor de este perímetro, que es en realidad, todo el espacio disponible para que el público pueda conocer, mirar, y reflexionar con el significado histórico y humano del lugar.

En este sentido, lo primero que se ve en el espacio perimetral es un conjunto de elementos escultóricos que serían los elementos externos principales que caracterizan al Patio 29. Estas esculturas serían unas grandes piezas metálicas que asemejan en su actitud a las personas que vivieron este lugar desde el dolor, incertidumbre y conmoción por los hechos que aquí ocurrieron. Son elementos que pretenden dar homenaje a los familiares de los desaparecidos, quienes son las personas que utilizaron este lugar y de alguna manera lo hicieron propio.

Estos elementos dialogan con las sepulturas, con los árboles existentes, desfilan en procesión, se agrupan en las esquinas, en torno a los árboles, y además funcionan como soporte de textos y como mobiliario para los visitantes. En estas esculturas se inscribirían textos o frases redactadas por los familiares de detenidos desaparecidos que deseen expresar su sentir y sus reflexiones sobre la historia que guarda el Patio 29. Es un glosario de frases o ideas sobre el significado del lugar como también una narración de la vida que se ha dado en torno a este Patio.

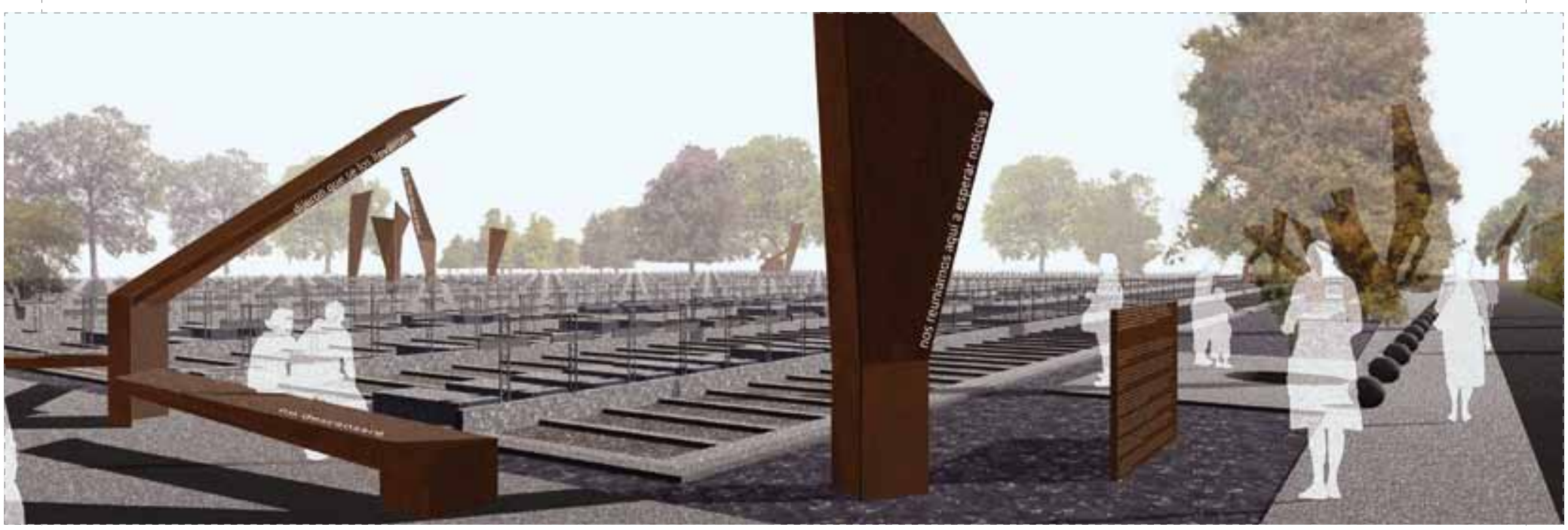




\section{N 018}

de arquitectura
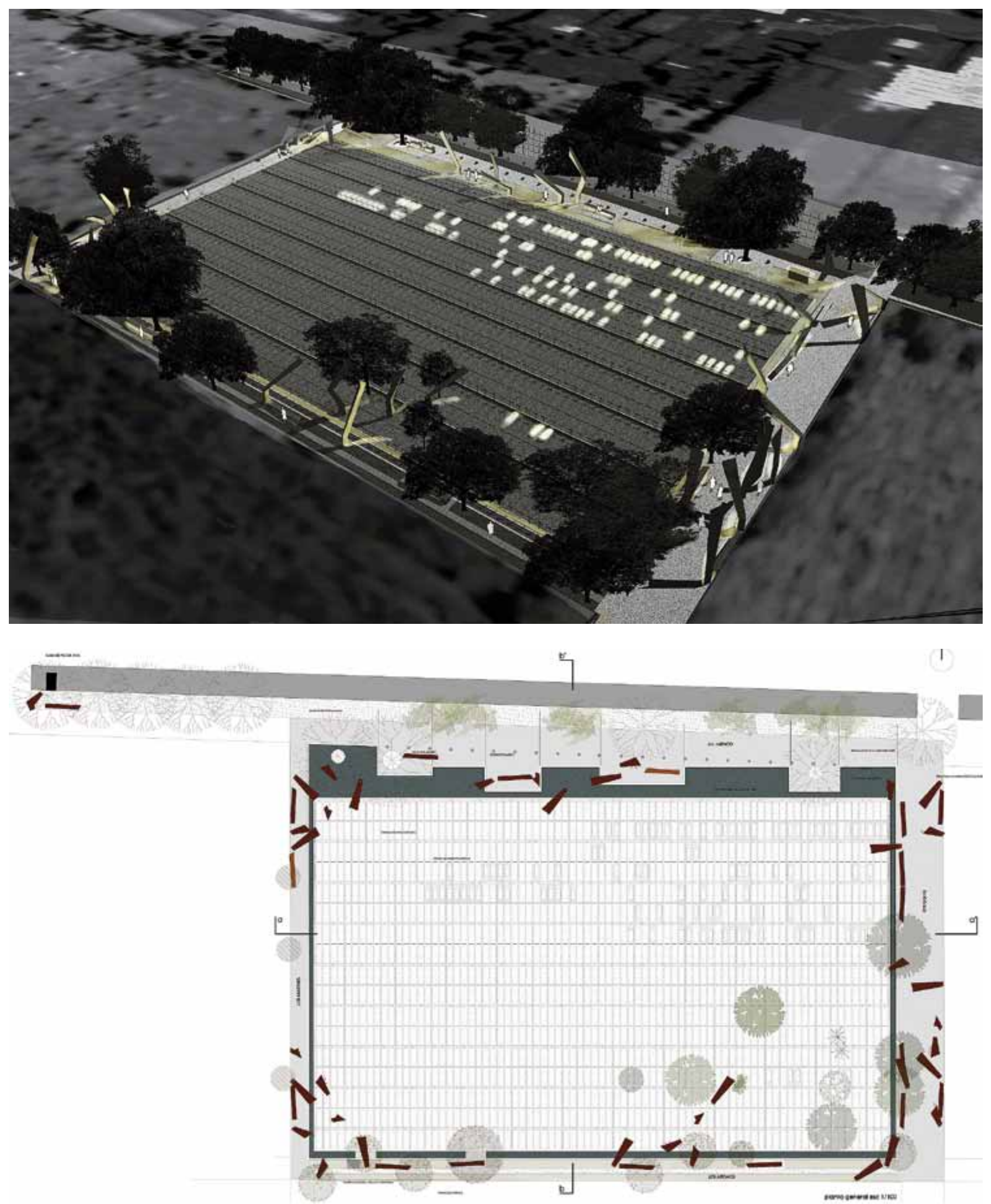

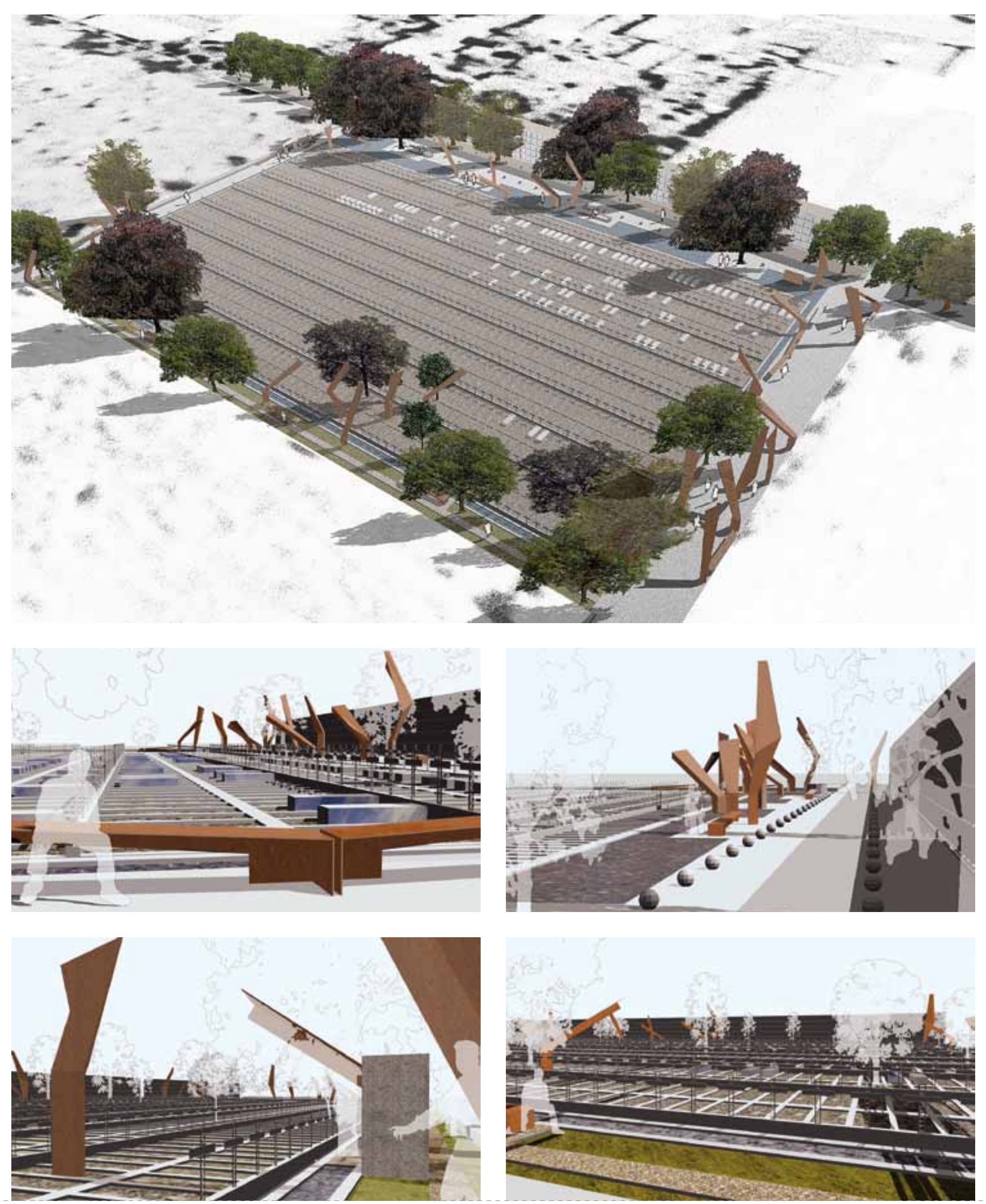